\title{
AS CONFIGURAÇÕES GENÉRICAS E MULTIMODAIS DO VIDEOCLIPE
}

\author{
Leonardo Mozdzenski ${ }^{1}$
}

\begin{abstract}
RESUMO
Apesar da sua crescente circulação social e popularização nos meios de comunicação de massa (televisão, internet e variados dispositivos eletrônicos móveis, tais como tablets e celulares), o gênero videoclipe ainda não tem recebido a devida atenção das pesquisas linguísticas e discursivas. Norteado pelo intuito de sanar essa omissão e buscando adotar uma abordagem multidisciplinar para esse objeto, este trabalho lança mão de pressupostos da sociorretórica e dos estudos da multimodalidade textual com o propósito de estabelecer uma categorização das configurações genéricas dos clipes. Para tanto, utiliza-se como critério a saliência dos atributos observados na sua organização composicional, estilo, conteúdo temático e na sua dinâmica. Com isso, esta investigação procura empregar um parâmetro único, coerente e suficientemente amplo, aprimorando as classificações atuais, bastante inconsistentes e/ou demasiado rebuscadas. Outro diferencial da presente proposta tipológica consiste em associar a cada configuração uma potencial autoimagem construída pelo/a cantor/a no vídeo musical - algo que, até o momento, ainda não havia sido contemplado de forma sistemática pelos demais pesquisadores da área. Para o corpus analítico, foram selecionados os seguintes videoclipes da cantora norte-americana Madonna: Material girl (1985), Vogue MTV's 1990 Music Video Awards (1990), Bedtime story (1995) e Hollywood (2003). Como resultado da análise, é possível propor as seguintes configurações genéricas básicas para o estudo dos clipes: a) videoclipes com saliência na performatividade; b) videoclipes com saliência na ficcionalidade; e c) videoclipes com saliência na artisticidade.
\end{abstract}

Palavras-chave: Videoclipe. Gênero textual. Multimodalidade. Configurações genéricas.

\section{ALGUMAS REFLEXÕES INICIAIS SOBRE A MULTIMODALIDADE}

Nas últimas décadas, particularmente com o advento da chamada "era eletrônica" (McLUHAN, 1974), o mundo ocidental vem testemunhando uma significativa mudança nas formas de produzir e ler os textos que circulam socialmente. Até há pouco tempo, os modos de representação comunicacional dos textos verbais (fala e escrita) e não-verbais (imagens, sons, gestos, etc.) eram tratados de maneira isolada e estanque, segundo as suas especificidades. Essas fronteiras, no entanto, tornam-se cada vez mais tênues. 
Como salientamos em Mozdzenski (2008), ilustrações, fotos, gráficos e diagramas, aliados a recursos de composição e impressão, como tipo de papel, cor, diagramação da página, formato das letras, etc., vêm sendo sistematicamente conjugados aos gêneros discursivos escritos. De acordo com Joly (2004, p. 133), "as palavras e as imagens revezam-se, interagem, completam-se e esclarecem-se com uma energia revitalizante. Longe de se excluir, as palavras e as imagens nutrem-se e exaltam-se umas às outras"

Já para Lemke (2002), as representações verbais e visuais coevoluíram histórica e culturalmente, para se complementarem mutuamente, coordenando-se entre si. Com isso, os textos passam a ser percebidos como construtos multimodais, dos quais a escrita é apenas um dos modos de representação das mensagens. Analogamente, nos gêneros discursivos orais, a análise da fala não pode mais prescindir dos gestos, entonações, expressões faciais, etc., presentes em quaisquer trocas verbais (KRESS e VAN LEEUWEN, 1996, 2001; JEWITT e KRESS, 2003).

A necessidade desse 'novo olhar' sobre o texto é premente, sobretudo se for observada a multígena produção textual veiculada pelos meios de comunicação de massa. Nos jornais impressos e revistas, por exemplo, é possível notar a constante interação entre a escrita e um número variado de modos semióticos, exercendo uma função retórica na construção de sentidos.

Nesse verdadeiro "hibridismo semiótico" - conforme expressão cunhada pelo The New London Group (2000) - o processamento textual das informações só pode se dar com a leitura integrada do texto verbal e do material visual, isto é, fotografias, infográficos, desenhos, símbolos e ícones, além do emprego de diversas cores e da elevada informatividade visual do layout. Caso contrário, a leitura lacunosa poderá afetar significativamente a compreensão da unidade global do texto.

Vale frisar, inclusive, que a elevação de status dos gêneros multimodais como objeto de análise da Linguística só aconteceu recentemente. Apesar de, em outras disciplinas, o estudo dos signos já ocorrer desde as décadas de 1950/60, somente nos últimos anos é que vem sendo realizada no campo da Linguística uma pesquisa mais sistemática e integralizada sobre o texto multimodal, abarcando conjuntamente todos os recursos semióticos que o compõem e considerando a sua inserção na chamada "sociedade da imagem" (JAMESON, 1994).

Aliás, embora seja consensual a constatação de que a "cultura contemporânea é sobretudo visual" (PELLEGRINI, 2003, p. 15), a incorporação da 
imagem e de outros recursos semióticos às análises linguísticas ainda encontra resistência em certas abordagens mais tradicionais. Como ressaltam Kress, LeiteGarcía e Van Leeuwen (2000), historicamente a análise do discurso se concentrou em textos linguisticamente realizados, valorizando-se a linguagem verbal nas modalidades oral e escrita, em detrimento de outros modos semióticos. Para esses autores, um texto multimodal deve ser lido em conjunção com todos os outros modos semióticos desse texto.

Dentro dessa perspectiva, a análise linguística tradicional tem que ser repensada, pois, como afirmam Kress e Van Leeuwen (1996, p. 8), "descrever uma 'língua' é descrever o que as pessoas fazem com as palavras, as imagens ou a música". Também no entendimento de Fairclough (2001, p. 23), "é muito apropriado estender a noção de discurso a outras formas simbólicas, tais como imagens visuais e textos que são combinações de palavras e imagens". Ou seja, nos atuais estudos linguísticos, é imprescindível uma revisão (e ampliação) do conceito de 'discurso', para que não deixem de ser abarcados todos os elementos semióticos das práticas sociais.

É com base nesses pressupostos que defendemos a necessidade de um olhar discursivo sobre as imagens e de um olhar multissemiótico sobre qualquer texto. Para tanto, propomos aqui discutir o videoclipe como um gênero textual flagrantemente multimodalizado. Por fim, sem ter a pretensão de aprofundar aqui esse complexo tema, reportamo-nos ao trabalho de Van Dijk (2008), para quem o discurso deve ser entendido como qualquer forma de uso da linguagem em textos falados ou escritos, em um sentido semiótico amplo. Para o autor,

Isso inclui estruturas visuais, tais como layout, tipo de letra ou figuras, para textos escritos ou impressos; e gestos, expressões faciais e outros signos, para a interação falada. Esse conceito de discurso também inclui combinações de sons e imagens nos muitos discursos multimidiáticos híbridos, como no cinema, na televisão, nos telefones celulares, na internet e em outros canais e veículos de comunicação. (VAN DIJK, 2008, p. 116).

\section{ESTUDO DOS VIDEOCLIPES: UMA BREVE INTRODUÇÃO}

Grande parte da dificuldade encontrada para investigar o videoclipe advém do preconceito subjacente por ser considerado um produto cultural não apenas inferior, já que a sua natureza é eminentemente mercadológica e não artística, mas também secundário, uma vez que o 'produto principal' seria a música ou o artista a ser 
divulgado e não o clipe em si. Se isso já é uma verdade no âmbito das Ciências da Comunicação - locus privilegiado de estudo dos gêneros audiovisuais em geral -, no domínio da Linguística, então, os videoclipes são praticamente ignorados.

A inexistência de estudos acadêmicos mais sistemáticos sobre o clipe numa perspectiva retórico-discursiva é ainda mais surpreendente se considerarmos os seguintes aspectos:

a) com sua crescente popularização nos meios de comunicação de massa sobretudo a partir dos anos 1980, os videoclipes tornaram-se um dos principais gêneros midiáticos de expressão cultural e estética da contemporaneidade, "marcando e modelando nossa cultura cotidiana: filme, arte, literatura, publicidade - todos claramente se acham sob o impacto dos clipes em sua estética, seus procedimentos técnicos, mundos visuais ou estratégias narrativas" (KEAZOR e WÜBBENA, 2010, p. 7);

b) o clipe é um gênero audiovisual multifacetado que revela uma tendência atual de integração de um grande número de recursos e estratégias multissemióticos ainda pouco explorados pela Linguística -, tendo por finalidade captar e manter a atenção do espectador (SEDEÑO VALDELLÓS, 2007);

c) o videoclipe constitui um gênero bastante apropriado para observar a construção identitária de cantores e cantoras, uma vez que consiste no "resultado de um processo de midiatização da performance musical [...], uma tentativa de síntese, num produto audiovisual, de um senso de personalidade do artista musical" (SOARES, 2009, p. 60. Grifou-se).

d) em qualquer investigação sobre gêneros midiáticos contemporâneos - e, em especial, sobre clipes -, as múltiplas possibilidades de produção de sentido demandam a convergência de vários aportes teóricos para dar conta de sua explicação (RYBACKI e RYBACKI, 1999), algo não satisfatoriamente contemplado pela literatura sobre o tema até o momento

$\mathrm{Na}$ realidade, grande parte da literatura atual sobre o videoclipe - com raras exceções, tais como Machado (1993, 1997, 2001), Soares (2004, 2009) e alguns outros poucos autores - parece estar circunscrita a apenas dois pontos de vista: as abordagens pós-modernas e os Estudos Culturais (BARRETO, 2005).

A crítica pós-moderna (e.g., KAPLAN, 1993; JAMESON, 1994) restringe-se a enquadrar os videoclipes como um típico produto da pós-modernidade, ressaltando a sua instabilidade, superficialidade e fragmentação. Para Connor (1993, p. 130- 
131), esse tipo de perspectiva em nada contribui para a compreensão do gênero, pois define o videoclipe pós-moderno pelo que ele não é: "como (não) narrativa, como (não) centrado, oferecendo (nenhuma) posição ao espectador".

Por sua vez, os Estudos Culturais (e.g., GOODWIN, 1992; STRAW, 1993) tendem a centrar-se demasiadamente na relação dos videoclipes e seus entornos sociais e econômicos, enfatizando questões ligadas ao racismo e diferenças étnicas, ao preconceito social, à discriminação sexual, ao consumo de produtos culturais, etc. Esse olhar mais 'macro' sobre os clipes finda por reduzir a importância do seu componente estético, essencial à compreensão do gênero: "Esteticamente, seus textos [dos clipes] constroem sentidos através de práticas, linguagens, sintaxes, iconografias e retóricas específicas" (GROSSBERG, 1993, p. 185-186).

Nesse cenário, os vídeos musicais constituem um excelente material para investigar a multimodalidade textual. Isso ocorre uma vez que usualmente orquestram, em um mesmo discurso multimodal, os seguintes elementos:

- textos verbais essenciais: letras das canções (canção = letra + melodia);

- textos verbais acessórios: por exemplo, diálogos incidentais ou elementos textuais gráficos integrantes das imagens do próprio videoclipe;

- componentes paratextuais: créditos e textos informativos que acompanham marginalmente os clipes, inseridos pelos canais televisivos, tais como nome do artista, título da canção e do álbum, gravadora, diretor do vídeo, logotipo do canal, etc.;

- música: organização melódica, rítmica e harmônica das canções;

- sons eventuais: ruídos e efeitos sonoros, como por exemplo, sons de motor de carro, trovões, pássaros cantando, etc.;

- imagem: cor, iluminação, angulação e velocidade de câmera, montagem e edição, layout da tela, e uma série de outros modos semióticos imagéticos que Ihe são característicos.

Todos esses elementos podem vir combinados através de infinitas maneiras para compor o videoclipe. Mas como conceituar esse gênero? Pontes (2003, p. 48) apresenta a seguinte definição:

O que é um videoclipe? Diremos que videoclipe é um pequeno filme, um curtametragem, cuja duração está atrelada (mas não restrita) ao início e fim do som de uma única música. Para ser considerado um videoclipe, este curta-metragem não pode ser jornalístico, não é a simples filmagem da apresentação de um ou mais 
músicos. Ele é a ilustração, a versão filmada, de uma canção. Há intenções artísticas em sua realização, e, quase sempre, ausência de linha narrativa.

Apesar de discordar da afirmação de que nos clipes há "quase sempre, ausência de linha narrativa", julgamos que essa definição sintetiza adequadamente o que vem a ser um videoclipe. É importante ressaltar, entretanto, que os videoclipes, enquanto gênero, possuem fins publicitários como propósito comunicativo fundamental. Apesar de cada vez mais os vídeos assumirem uma 'feição artística' e utilizarem um sofisticado aparato tecnológico fílmico em sua produção, eles são realizados basicamente para vender uma canção, bem como todos os demais produtos dela derivados: CDs, DVDs, ingressos para shows, memorabília, etc.

Além dessa perspectiva estritamente comercial, no entanto, o videoclipe ainda possui uma outra finalidade tão ou mais importante do que vender uma canção: ele deve vender a imagem do/a artista. Esse é, inclusive, um dos aspectos que despertam maior interesse sob o ponto de vista retórico no estudo dos vídeos musicais (SOARES, 2009).

Vistos, assim, os principais propósitos comunicativos dos clipes, cabe agora procurarmos uma definição mais precisa da natureza desse gênero textual a partir de um olhar sociorretórico. Para Machado (2001), o videoclipe encontra-se compreendido na constelação dos gêneros televisivos. Uma vez que atualmente os vídeos musicais circulam pelas mais diferentes mídias e suportes (além da TV, temos plataformas de compartilhamento de vídeos na internet, aparelhos eletrônicos tais como smartphones e tablets, etc.), adotaremos aqui uma perspectiva mais ampla.

Os videoclipes são ora considerados como um gênero audiovisual do domínio do entretenimento, de natureza eminentemente publicitária, não raro assumindo uma compleição artística. Isto é, o clipe não apenas opera para a autopromoção mercadológica (da imagem) do/a artista e seus 'produtos', mas também promove, muitas vezes, a fruição estética de uma 'obra de arte' audiovisual - algo ainda mais usual nos vídeos contemporâneos. Mas em termos dos estudos retóricos e multimodais, como é possível compreendermos a configuração de um gênero tão multifacetado? É o que discutiremos a seguir. 


\section{AS CONFIGURAÇÕES GENÉRICAS E MULTIMODAIS DO VIDEOCLIPE}

Muito se tem debatido acerca das configurações do videoclipe enquanto gênero. Contudo, diante da grande variedade de opiniões e propostas tipológicas, é possível concluir ser esta uma questão longe de ser resolvida de forma consensual entre os especialistas na área.

Como vimos anteriormente, ao contrário de outros campos que se dedicam ao estudo de produtos culturais mais 'sérios' - tais como literatura e cinema, por exemplo -, apenas uma pequena parcela de pesquisas acadêmicas mais sistemáticas é produzida tendo como objeto o videoclipe. Aliada a esse preconceito acadêmico, a alegada natureza fluida e fragmentária dos clipes torna ainda mais difícil a construção de uma proposta harmônica e convergente de categorização desse gênero.

Alguns outros pesquisadores clássicos sempre mencionados atualmente por exemplo, Lynch (1984), Kaplan (1987), Goodwin (1987), Gow (1992), entre outros -apresentaram variadas tentativas de categorizar os videoclipes. Em comum, grosso modo, essas propostas nem sempre adotam critérios classificatórios coerentes, além de deixar de considerar uma série de elementos essenciais à compreensão de todo gênero textual: seus conteúdos, suas propriedades funcionais e sua composição característica.

Longe de ter a pretensão de construir um modelo requintado e revolucionário de compreender os videoclipes enquanto gênero, partiremos da tripartição clássica de Firth (1988) em videoclipes de performance, narrativos e conceituais, propondo tomarmos aqui como o critério categorizador fundamental a saliência - no sentido empregado por Schmid (2007) - dos atributos que são observados na sua organização composicional, estilo, conteúdo temático e na sua dinâmica.

Além disso, cabe ressaltar que, de acordo com Firth (1988), um dos principais propósitos do clipe não é exatamente promover uma canção individual, mas sim o/a cantor/a ou a banda que a executa. Assim sendo, levando-se em conta esse fato e tendo em vista os nossos objetivos, o modelo sugerido abaixo também irá contemplar que a autoimagem do/a artista/banda está sendo privilegiadamente construída a partir dessas categorias. Até o momento, esse aspecto ainda não havia sido expressamente contemplado por nenhuma das propostas de categorização dos clipes. Ao final de cada item, apresento como exemplo um videoclipe da cantora 
norte-americana Madonna como "tipo ideal" (cf. DIEHL, 2004), a título de ilustração. A escolha pelos clipes da popstar se deu, em primeiro lugar, em função da sua vasta carreira videográfica, o que permite um leque mais amplo de opções e de possibilidades de comparação com base nas categorias examinadas. Além disso, como argumenta Kellner (2001), os vídeos de Madonna parecem ser produzidos sobretudo para criar e recriar uma 'persona de estrela' da cantora. Como o nosso escopo aqui também é, observamos de que modo se dá essa construção da imagem feminina nos videoclipes, Madonna parece ser, pois, uma das candidatas mais 'versáteis' para cumprir esse papel.

Isso posto, foi possível identificar três possíveis categorizações para os videoclipes com base na saliência da construção composicional, do estilo, do tema e da dinâmica desse gênero:

\subsection{Saliência na performatividade}

Os videoclipes que utilizam esse tipo de configuração procuram evidenciar a capacidade técnica da artista, quer como uma musicista profissional (no caso de bandas cujas integrantes aparecem tocando 'ao vivo', por exemplo), quer como vocalista (sobretudo nos vídeos centrados na cantora dublando a canção), quer como dançarina (naqueles clipes em que a cantora aparece dançando). É possível conceber dois tipos básicos de videoclipes nessa configuração: os que possuem o efeito de autenticidade e os que não possuem.

No primeiro caso, encontram-se aqueles clipes que consistem em registros ao vivo de uma apresentação da cantora ou da banda, podendo ser incluídas imagens adicionais do backstage. As artistas são retratadas em seu 'ambiente natural' sobre os palcos, dando ao espectador a sensação de estar assistindo a um show ao vivo e tendo acesso privilegiado aos bastidores, aos ensaios, às gravações em estúdio e ao dia a dia da cantora/banda 'na estrada'. Para provocar ou acentuar esse efeito de autenticidade, é comum empregar recursos técnicos variados, tais como filmagem em preto e branco, imagens granuladas, uso de câmeras 'tremidas' imprimindo 'espontaneidade' ao registro, aparente desleixo na montagem final das imagens conferindo-Ihes 'naturalidade', etc.

Já no caso dos vídeos sem efeito de autenticidade, a performance da cantora ou da banda é explicitamente realizada para a produção do clipe. Sem qualquer 
pretensão de parecer um registro 'natural', a produção do videoclipe utiliza uma série de estratégias típicas dessa configuração: a artista olha diretamente para a câmera, normalmente dublando a canção para as lentes/o espectador; a cantora se junta a dançarinos fazendo coreografias em sets (físicos ou virtuais) especialmente desenhados e construídos para o clipe ou em locações externas reservadas para o mesmo fim; o encadeamento sequencial das cenas (i.e., a montagem do vídeo) nem sempre segue uma ordem 'lógica', sendo mais importante mostrar a artista em diferentes cenários com diferentes looks; etc.

A autoimagem construída nos videoclipes que salientam a performatividade da cantora tende a destacar a sua identidade como performer, isto é, como alguém com talento e habilidades artísticas especiais, como uma pessoa dotada de credibilidade profissional como música, cantora, dançarina, etc. E, portanto, como uma estrela com legitimidade para aparecer à frente de um clipe e entreter o espectador. Em geral, isso envolve também atributos mais 'subjetivos' da artista, tal como demonstrar uma certa 'atitude' através de suas performances videoclípticas, evidenciando certos valores e ideais incorporados à sua persona: ela é 'rebelde', ou 'diva', ou 'excêntrica', etc.

Como exemplo de videoclipe centrado na performatividade com efeito de autenticidade, podemos citar o registro da apresentação ao vivo da canção "Vogue", durante o MTV's 1990 Music Video Awards, realizado em Los Angeles em 06/09/1990². Na ocasião, Madonna surpreendeu seus fãs com uma proposta visual completamente distinta do vídeo original, o qual promovia um glamour nostálgico das divas hollywoodianas dos anos 1940/50. Já na premiação promovida pela MTV americana, a popstar retoma outro grande ícone: a última rainha francesa, Maria Antonieta.

Com essa sua homenagem, a cantora promove a imagem de um glamour mais 'épico'. Ao incorporar Maria Antonieta e sua corte, usando perucas imponentes e um opulento vestuário, Madonna evoca símbolos não apenas das extravagâncias da jovem monarca, mas também dos derradeiros suspiros de um modo de vida abastado e luxuoso, típico da nobreza europeia pré-Revolução Francesa. O sucesso da performance foi tanto que a apresentação acabou integrando a videografia oficial da artista no DVD The Immaculate Collection (1990).

Por sua vez, um típico exemplo de videoclipe centrado na performatividade sem buscar o efeito de autenticidade é Hollywood (Madonna, 2003) ${ }^{3}$. Dessa vez, o 
glamour segue uma proposta fashion estilizada, com clara inspiração no fotógrafo de moda Guy Bourdin. Madonna reforça sua autoimagem de 'camaleônica' e de que está sempre se reinventado ao assumir os mais diversos looks/atitudes: morena pinup, ruiva exibicionista, diva platinada, loura vaidosa, entre tantas outras personas.

A 'capacidade técnica' da popstar é medida aqui não apenas pela quantidade de visuais que ela consegue adotar, mas também por sua habilidade física - através de recorrentes cenas salientando a sua flexibilidade e a sua boa forma -, bem como sua 'sensualidade' manifesta por meio de uma infinidade de caras e bocas ao longo do vídeo. Madonna constrói a imagem de uma mulher que, no auge dos seus (então) 45 anos, pode ser sexy e glamorosa, além de demonstrar um excelente condicionamento físico.

\subsection{Saliência na ficcionalidade}

Os videoclipes com configuração ficcionalizante são os que narram uma história. Essa narrativa visual, no entanto, nem sempre corresponde à 'visualização literal' da letra da canção; antes, pode ilustrá-la livremente, complementar ou ampliar seus sentidos ou ainda funcionar de modo totalmente independente. Dessa forma, também é possível que a narrativização visual de uma música passe a produzir sentidos tão novos a ponto de modificar significativamente a leitura de sua letra. É o caso, como veremos a seguir, do videoclipe Material girl (Madonna, 1985), cuja canção supostamente valorizaria o mundo materialista, mas, a partir do vídeo, podese perceber que se trata de uma grande ironia.

Apesar de serem caracterizados por representar uma sucessão de acontecimentos mais ou menos encadeados, os clipes com essa configuração não seguem necessariamente uma ordem cronológica e diegética 'canônica'. Assim, são frequentes os 'saltos narrativos', bem como a alternância rápida e a sobreposição de planos, sobretudo devido ao curto tempo disponível para contar aquela história, normalmente adstrita aos 4 ou 5 minutos de duração do videoclipe. Além disso, de maneira geral, os vídeos com essa configuração intercalam momentos entre a história narrada e a performance da cantora ou da banda, que pode ou não estar integrada à narrativa.

O uso da narrativa no videoclipe é um recurso bastante empregado como estratégia de produzir a autoimagem da artista. Os diversos tipos de histórias Signo [ISSN 1982-2014]. Santa Cruz do Sul, v. 38, n. 64, p. 100-117, jan./jun. 2013. 
contadas (românticas, cômicas, engajadas, sensuais, polêmicas, aventureiras, violentas, etc.) operam para legitimar não apenas as emoções de que tratam as canções, mas principalmente a identidade da cantora ou da banda na cena musical: é uma artista romântica, cômica, engajada e assim por diante.

Nesse sentido, ainda contribuem para a construção dessa imagem os demais elementos integrantes da visualização da narrativa: as locações em que a história do clipe foi filmada (se foi numa ilha paradisíaca ou nas ruas de uma favela, por exemplo), as personagens que participam da trama (principalmente se a cantora ou se as integrantes da banda também estiverem atuando no elenco), o estilo de filmagem (se o clipe simula um longa-metragem - por exemplo, com créditos de abertura - ou se 'mimetiza' o estilo de cineastas consagrados ou de gêneros cinematográficos clássicos), etc.

Um exemplo de clipe que privilegia a ficcionalidade é Material girl (Madonna, $1985)^{4}$. Aqui, a cantora 'interpreta' uma estrela em ascensão. O vídeo intercala dois núcleos ficcionais-narrativos mais evidentes: como destaque principal, exibe a performance da cantora à Marilyn Monroe, quase reproduzindo a dance routine original do número musical "Diamonds are a girl's best friend". Paralelamente, mostra conta o backstage cenográfico da gravação dessa performance, contando o 'drama' vivo pela popstar, que recusa presentes suntuosos e mostra-se insatisfeita com seus pretendentes endinheirados, ficando ao final com um aparente pobretão.

\subsection{Saliência na artisticidade}

Os videoclipes compreendidos nesta categoria são constituídos por aqueles produtos culturais que buscam despertar nos espectadores uma sensação estética de que estão assistindo a uma obra artística. A ideia aqui não é promover diretamente a cantora através da sua performance ou contando uma história. Procura-se, ao contrário, representar a subjetividade da artista por meio da expressão de uma experiência estética, sensorial, emocional, etc. Apesar de apresentar certas semelhanças com a videoarte (YOSHIURA, 2007), é importante frisar que os videoclipes 'artísticos' se distinguem por seus propósitos sobretudo comerciais e mercadológicos (divulgar a performer e vender seus CDs, DVDs, memorabília e ingressos de shows) ${ }^{5}$. 
O efeito artístico desses videoclipes é produzido de forma bastante diversificada. Pode-se utilizar, por exemplo, uma sequência de imagens abstratas, objetivando a apreciação visual puramente estética, sem pretender a representação física de pessoas, objetos, paisagens, etc. e combinando luzes, cores, movimentos e sons. Também é possível usar técnicas do cinema experimental. O surrealismo é ainda outro movimento cuja proposta estética é sempre retomada nesses clipes, com a ênfase que é dada ao pensamento espontâneo e incoerente, ao sonho, ao inconsciente.

Ao levarem o espectador à fruição do clipe como uma 'obra de arte', os videoclipes aqui tratados buscam mobilizar a identidade de 'artista séria' que produz um 'trabalho sério', de qualidade 'artística', e não meramente bem consumível e descartável como os demais vídeos. Cria-se, portanto, a autoimagem de uma cantora legitimada como alguém que entende e produz arte 'de verdade' e cujo trabalho videoclíptico atesta a sua 'credibilidade artística'.

Um típico exemplo dessa categoria é o clipe Bedtime story (Madonna, 1995). Como afirma uma biógrafa da cantora, "o videoclipe passou pelos portais da alta arte, e foi exibido em diversas galerias, entrando para a coleção permanente do London's Museum of Moving Image" (O’BRIEN, 2008, p. 274). Ao custo de 5 milhões de dólares, o vídeo - até então o mais caro já rodado - acumulou vários prêmios e, mais recentemente, em 2005, também passou a integrar a coleção permanente do Museum of Modern Art (MoMA) de Nova York (LEVY, 2011).

O videoclipe consiste, de fato, numa grande sucessão de imagens de franca inspiração surrealista, evocando, sem aparente coerência, um imaginário de sonho, de irrealidade, do inconsciente. Vários blogs de fãs e acaloradas discussões em redes sociais se dedicaram a 'desvendar' todas as referências imagéticas explícitas ou subliminares, propositais ou inconscientes, acaso existentes. É o caso da 'releitura' dos seguintes quadros: Reflejo lunar (1957), Nacer de nuevo (1960) e Los amantes (1963) da artista plástica espanhola Remedios Varo; The giantess (1950), da pintora britânica Leonora Carrington; The ends of the Earth (1949), L'Amitié (1958) e Vision roja (1984) da pintora argentina Leonor Fini; bem como Diego y yo (1949), da artista plástica mexicana Frida Khalo.

Assim, no videoclipe Bedtime story, ao dialogar com essas e inúmeras outras pinturas de artistas consagradas do movimento surrealista, Madonna constrói para si uma imagem de 'artista autêntica', séria, respeitável, culta, afastando-se, portanto, Signo [ISSN 1982-2014]. Santa Cruz do Sul, v. 38, n. 64, p. 100-117, jan./jun. 2013.

http://online.unisc.br/seer/index.php/signo 
da mera aura de popstar efêmera, superficial e hipersexualizada que a acompanhava. Aparentemente, não só deu certo - como se comprova pela inclusão desse vídeo no acervo de museus internacionais de renome -, mas também gerou frutos.

\subsection{As três configurações dos videoclipes}

Vistas essas três possibilidades de configuração do videoclipe (performativa, ficcional e artística), é importante ressaltar que, em muitos casos, essas categorias se misturam, tornando-se híbridas e nem sempre com fronteiras bem delimitadas. Levando-se esse aspecto em consideração, apresentamos o Diagrama 1 a seguir, como modo de visualizar esquematicamente de que maneira essas três configurações possíveis do videoclipe podem operar em situações concretas.

Mediante essa representação gráfica, fica claro perceber e situar os casos em que uma das configurações (performativa, ficcional ou artística) ocorre em sua forma mais 'pura' (áreas nas cores amarelo, rosa e azul-claro, respectivamente) ou quando há uma interseção entre duas configurações (isto é, quando o clipe veicula elementos comuns a duas categorias, tal como representado pelas áreas nas cores vermelho, verde e azul-escuro) ou ainda se o vídeo apresenta uma hibridização de todas essas possibilidades (área central na cor preta).

\section{Diagrama 1 - 0 gênero videoclipe e suas configurações}

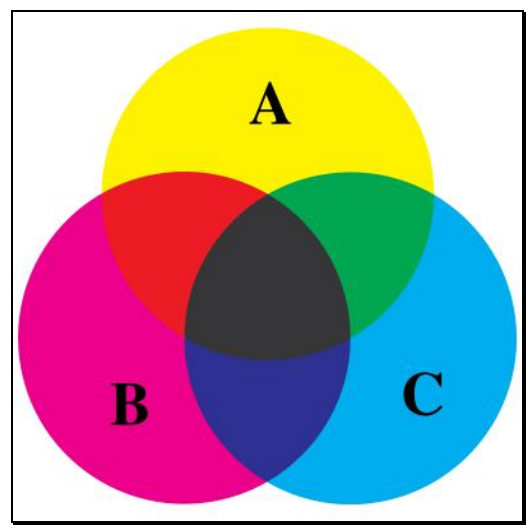

LEGENDA:

(A) Videoclipes com saliência na performatividade

(B) Videoclipes com saliência na ficcionalidade

(C) Videoclipes com saliência na artisticidade 


\section{CONSIDERAÇÕES FINAIS}

O pressuposto de que o objeto da Linguística não deve se restringir à análise do material verbal presente nos textos permeia, na verdade, todo este artigo. Apesar da resistência de algumas correntes mais tradicionais, é possível constatar que, aos poucos, os estudos linguísticos mais modernos estão passando a atentar para as mais variadas modalidades presentes em todas as trocas comunicativas.

Trabalhar com um gênero tão multifacetado como o videoclipe e procurar estabelecer critérios para compreender suas configurações também podem constituir uma excelente atividade para a sala de aula. Esse é o pensamento de Duarte (2002), ao defender que o domínio dos códigos e signos que compõem a linguagem audiovisual constitui uma forma de poder nas sociedades que produzem e consomem artefatos culturais dessa natureza. Assim, para a pesquisadora, "é tarefa dos meios educacionais oferecer os recursos adequados para a aquisição desse domínio e para a ampliação da competência para ver, do mesmo modo como fazemos com a competência para ler e escrever" (DUARTE, 2002, p. 82).

É necessário mudarmos essa perspectiva dicotômica ainda majoritária de que 'texto é para ler' x 'imagem é para ver'. Esperamos, assim, que este artigo seja um convite aberto a pesquisadores não só de Linguística, como também dos mais variados campos do conhecimento a se aventurarem, em suas respectivas especialidades, pelo fascinante universo multimodal do videoclipe ${ }^{7}$.

\section{NOTAS}

${ }^{1}$ Doutor em Letras/Linguística pela Universidade Federal de Pernambuco. É autor de Multimodalidade e gênero textual: analisando criticamente as cartilhas jurídicas (Ed. UFPE, 2008).

${ }^{2}$ Disponível em: <http://www.youtube.com/watch?v=ITaXtWWR16A> (acesso em: 28 fev. 2013).

${ }^{3}$ Disponível em: <http://www.youtube.com/watch?v=_iT3ia_V68Q> (acesso em: 28 fev. 2013).

${ }^{4}$ Disponível em: <http://www.madonna.com> (acesso em: 28 fev. 2013).

${ }^{5}$ Para uma discussão mais aprofundada acerca dos valores sociais, ideológicos, culturais, etc. que são difundidos nos videoclipes - sobretudo no que diz respeito ao debate feminismo $x$ pós-feminismo em clipes estrelados por cantoras -, consultar Mozdzenski (2012).

${ }^{6}$ Disponível em: <http://www.youtube.com/watch?v=iDbMHpE-Ohc> (acesso em: 28 fev. 2013).

${ }^{7} \mathrm{O}$ presente trabalho constituiu, na verdade, um recorte de um dos temas tratados na minha tese de doutorado, intitulada "O ethos e o pathos em videoclipes femininos: construindo identidades, encenando emoções” (MOZDZENSKI, 2012), orientado pela Professora Dra. Angela Paiva Dionisio.

Signo [ISSN 1982-2014]. Santa Cruz do Sul, v. 38, n. 64, p. 100-117, jan./jun. 2013.

http://online.unisc.br/seer/index.php/signo 
THE GENRE AND MULTIMODAL CONFIGURATIONS OF MUSIC VIDEO

\begin{abstract}
Despite their increasing popularity and social circulation in mass media (television, internet and various mobile electronic devices such as tablets and cell phones), the genre music video has not received a suitable attention by the discursive and linguistic research. Guided by the intend of remedying this omission and seeking to adopt a multidisciplinary approach to this object, this work makes use of the assumptions from social rhetoric and studies of multimodality for the purpose of establishing a categorization of the genre configurations of music videos. To do so, it uses as a criterion the salience of the attributes that stand out in their compositional organization, style, thematic content and their dynamics. Thus, this research seeks to employ a single parameter, consistent and sufficiently wide, improving the current classifications, quite inconsistent and / or too far-fetched. Another distinguishing feature of this typological proposal is to associate to each configuration a potential self-image built by a singer in the music video - something that, until now, had not been considered systematically by other researchers. For the analytical corpus, we selected the following music videos by American singer Madonna: Material Girl (1985), Vogue - MTV's 1990 Video Music Awards (1990), Bedtime Story (1995) and Hollywood (2003). As a result of analysis, it is possible to propose the following basic genre configurations for the study of clips: a) music videos with salience in performativity; b) music videos with salience in fictionality; and c) music videos with salience in artistry.
\end{abstract}

Keywords: Music video. Genre. Multimodality. Genre configurations.

\title{
REFERÊNCIAS
}

BARRETO, R.R. A fabricação do ídolo pop: a análise textual de videoclipes e a construção da imagem de Madonna. 2005. 197 f. Dissertação (Mestrado em Comunicação e Cultura Contemporâneas) - Programa de Pós-Graduação em Comunicação e Cultura Contemporâneas, Universidade Federal da Bahia, Salvador, 2005.

CONNOR, S. Cultura pós-moderna: introdução às teorias do contemporâneo. São Paulo: Loyola, 1993.

DIEHL, A.A. Max Weber e a história. 2. ed. Passo Fundo: UPF, 2004.

DUARTE, R. Cinema \& educação. Belo Horizonte: Autêntica, 2002.

FAIRCLOUGH, N. Discurso e mudança social. Brasília: UnB, 2001.

FIRTH, S. Music for pleasure. Cambridge: Polity Press, 1988. 
GOODWIN, A. Dancing in the distraction factory: music television and popular culture. Minnesota: University of Minnesota Press, 1992.

. Music video in the (post)modern world. Screen, v. 28, n. 3, p. 36-55, 1987.

GOW, J. Music video as communication: popular formulas and emerging genres. Journal of Popular Culture, v. 26, n. 2, p. 50-62, 1992.

GROSSBERG, L. The media economy of rock culture: cinema, postmodernity and autenticity. In: FRITH, S.; GOODWIN, A.; GROSSBERG, L. (Eds.). Sound \& vision: the music video reader. London/ New York: Routledge, 1993. p. 185-209.

JAMESON, F. Espaço e imagem: teorias do pós-moderno e outros ensaios. Rio de Janeiro: Editora da UFRJ, 1994.

JEWITT, C.; KRESS, G. (Eds.). Multimodal literacy. New York: Peter Lang, 2003.

JOLY, M. Introdução à análise da imagem. 7.ed. Campinas: Papirus, 2004.

KAPLAN, E. A. (Org.). O mal-estar do pós-modernismo: teorias, práticas. Rio de Janeiro: Jorge Zarzar Editor, 1993.

Rocking around the clock: music television, postmodernism and consumer culture. New York: Methuen, 1987.

KEAZOR, H.; WÜBBENA, T. Introduction. In: KEAZOR, H.; WÜBBENA, T. (Eds.). Rewind, play, fast foward: the past, present and future of the music video.

Piscataway (NJ): Transaction Publishers, 2010. p. 7-31.

KELLNER, D. Madonna, moda e imagem. In: KELLNER, D. A cultura da mídia estudos culturais: identidade e política entre o moderno e o pós-moderno. Bauru: EDUSC, 2001. p. 335-375.

KRESS, G.; LEITE-GARCÍA, R.; VAN LEEUWEN, T. Semiótica Discursiva. In: VAN DIJK, T.A. (Org.). El discurso como estructura y processo. Estudios del discurso: introduction multidisciplinaria. Vol. 1. Barcelona: Gedisa editorial, 2000. p. 373-416.

KRESS, G.; VAN LEEUWEN, T. Multimodal discourse: the modes and media of contemporary communication. New York: Oxford University Press, 2001.

KRESS, G.; VAN LEEUWEN, T. Reading images: the grammar of visual design. New York: Routledge, 1996.

LEMKE, J. L. Travels in hypermodality. Visual communication, SAGE Publications, v. 1, n. 3, p. 299-325, out. 2002.

LEVY, G. Top 10 music video directors who now direct movies: Mark Romanek. Time Specials, 14 jan. 2011. Disponível em:

<http://www.time.com/time/specials/packages/article/0,28804,2042089_2042088_20 41977,00.html>. Acesso em: 18 nov. 2011. 
LYNCH, J.D. Music videos: from performance to Dada-Surrealism. Journal of Popular Culture, v. 18, n. 1, p. 53-57, 1984.

MACHADO, A. O diálogo entre cinema e vídeo. In: cinemas. Campinas: Papirus, 1997. p. 202-220. . Pré-cinemas \& pós-

O vídeo e sua linguagem. Dossiê Palavra/Imagem - Revista USP, n. 16, p. 6-17, dez. 1992/fev. 1993.

Reinvenção do videoclipe. In: . A televisão levada a sério. São Paulo: SENAC, 2001. p. 173-196.

MCLUHAN, M. Os meios de comunicação como extensões humanas. São Paulo: Cultrix, 1974.

MOZDZENSKI, L. Multimodalidade e gênero textual: analisando criticamente as cartilhas jurídicas. Recife: Editora da UFPE, 2008.

. O ethos e o pathos em videoclipes femininos: construindo identidades, encenando emoções. 2012. 356 f. Tese (Doutorado em Linguística) - Programa de Pós-Graduação em Letras, Universidade Federal de Pernambuco, Recife, 2012. Disponível em: <http://www.pgletras.com.br/autores/tese2012-Leonardo-PinheiroMozdzenski.html>. Acesso em: 14 maio 2013.

O'BRIEN, L. Madonna - 50 anos: a biografia do maior ídolo da música pop. Rio de Janeiro: Nova Fronteira, 2008.

PELLEGRINI, T. Narrativa verbal e narrativa visual: possíveis aproximações. In: PELLEGRINI, T. et al. Literatura, cinema e televisão. São Paulo: Ed. Senac São Paulo / Instituto Itaú Cultural, 2003. p. 14-35.

PONTES, P. Linguagem dos videoclipes e as questões do indivíduo na pósmodernidade. Sessões do Imaginário, n. 10, p. 47-51, nov. 2003.

RYBACKI, K.C.; RYBACKI, D.J. Cultural approaches to the rhetorical analysis of selected music videos. Trans - Revista Transcultural de Música, n. 4, 1999. Disponível em: <http://www.sibetrans.com/trans/a254/cultural-approaches-to-therhetorical-analysis-of-selected-music-videos>. Acesso em: 5 dez. 2011.

SCHMID, H-J. Entrenchment, salience, and basic levels. GEERAERTS, D.; CUYCKENS, H. (Eds.). The Oxford handbook of cognitive linguistics. Oxford: Oxford University Press, 2007. p. 117-138.

SEDEÑO VALDELLÓS, A.M. El videoclip como mecanarrativa. Signa, n. 16, 2007, p. 493-504, 2007.

SOARES, T. 2004. Videoclipe: o elogio da desarmonia. Recife, Ed. do Autor. 
A construção imagética dos videoclipes: canção, gêneros e performance na análise de audiovisuais da cultura midiática. 2009. 302 f. Tese (Doutorado em Comunicação e Cultura Contemporânea) - Programa de Pós-Graduação em Comunicação e Cultura Contemporâneas, Universidade Federal da Bahia, Salvador, 2009.

STRAW, W. Popular music and postmodernism in the 1980s. In: FRITH, S.; GOODWIN, A.; GROSSBERG, L. (Eds.). Sound \& vision: the music video reader. London/ New York: Routledge, 1993. p. 3-21.

THE NEW LONDON GROUP. A pedagogy of multiliteracies: designing social futures. In: COPE, B.; KALANTZIZ, M. (Eds.). Multiliteracies: literacy learning and the design of social futures. New York: Routledge, 2000. p. 9-37.

VAN DIJK, T.A. Discourse and context: a sociocognitive approach. New York: Cambridge University Press, 2008.

YOSHIURA, E.V. Videoarte, videoclipe: investidas contra a "boa forma". São Paulo: Porto de Ideias, 2007. 